Coulthard, N. \& Ogden, J. (2018). The impact of posting selfies and gaining feedback ('likes') on the psychological wellbeing of 16-25 year olds: an experimental study. Cyberpsychology: Journal of Psychosocial Research on Cyberspace, 12(2), article 4. http://dx.doi.org/10.5817/CP2018-2-4

\title{
The impact of posting selfies and gaining feedback ('likes') on the psychological wellbeing of 16-25 year olds: an experimental study
}

\author{
Naomi Coulthard \& Jane Ogden \\ ${ }^{1}$ University of Surrey, Guildford, Surrey, UK
}

\begin{abstract}
Social media, and particularly posting 'selfies' have become fully incorporated into young people's lives. Research indicates that posting selfies may impact upon self esteem and that feedback in the form of 'likes' may change how young people feel about themselves. To date, however, most research has been cross sectional or qualitative limiting conclusions about causality. Further, it has taken place in non naturalistic environments, with no longer term follow up and limited outcome variables. This experimental study explored the impact of posting selfies and receiving feedback ('likes') on Instagram on broader aspects of the psychological well-being of young people. Participants $(n=59)$ aged 16-25 were randomly allocated to one of three conditions for a 7-day intervention (no selfie-posting; posting selfies without feedback; posting selfies with feedback) and completed measures at baseline, after the intervention and at one week follow up. 'Likes' were delivered through an app. The intervention had no impact on self-esteem or mood. Posting no selfies resulted in a greater improvement in appearance satisfaction over the study compared to posting selfies (regardless of feedback). In contrast, posting selfies with feedback resulted in a greater improvement in face satisfaction during the intervention although this dropped back to baseline by follow up. To conclude the impact of selfies may vary depending upon which outcome variable is measured and when.
\end{abstract}

Keywords: Social media; selfies; feedback; self-esteem; appearance satisfaction

\section{Introduction}

Much research has explored the impact of social media on the psychological wellbeing of young people and has highlighted a number of possible outcomes including body image, self esteem, mood and 'Facebook depression' (for reviews see Holland \& Tiggemann, 2016; Richards, Caldwell \& Go, 2015). One key part of the use of social media is the 'selfie' which is a 'self-portrait photograph of oneself' taken with a smartphone directed at the face, or at a mirror. Research indicates that social media platforms and recently, 'selfies' have become fully incorporated into young people's lives (Bond, 2016; Katz \& Crocker, 2015). As a result, teenagers and young adults are exposed to a self-portrait rich online-environment and peer feedback on a daily basis (Chua \& Chang, 2016; Mascheroni, Vincent, \& Jimenez, 2015; Valkenburg, Peter, \& Schouten, 2006). In particular, the social media platform 'Instagram' hosts 238 million photographs under the hashtag \#selfie, as well as a further 128 million under the hashtag \#me (Weiser, 2015). Further, the Oxford dictionary coined 'selfie' as the word of the year in 2013. Research on the use of 'selfies' has therefore proliferated over recent years. Research describing who posts selfies and why, the impact of selfies and the role that feedback and 'likes' play together with key theories will now be explored. Key gaps in the existing literature will then be identified to set the scene for the present study.

Selfies are mostly posted by females, adolescents and young adults (Dhir, Pallesen, Torsheim, \& SchouAndreassen, 2016; Katz \& Crocker, 2015) and a recent US survey indicated that $98 \%$ of their $18-24$ year old sample 
had posted a selfie on social media ever and $46 \%$ had posted on that day (Katz \& Crocker, 2015). In terms of why people post selfies, psychosocial theory suggests that it reflects young people's stage of development, in which identity is explored, and perceptions regarding appearance and weight are fragile (Arnett, 2000). In support of this notion, cross-cultural qualitative research consistently reveals 'identity play' motives behind selfies. For example, selfie-posting is commonly rationalised in terms of empowerment, identity experimentation and improving selfimage (Chua \& Chang, 2016; Katz \& Crocker, 2015; Mascheroni et al., 2015; Tiidenberg \& Cruz, 2015). Further, motives to post also appear to encompass peer-affirmation, which stabilises self-perceptions. For example, research suggests that social media 'likes', 'followers' and 'comments' are ways that peers can show this affirmation, and receiving selfie 'likes' is a key aim for young social media users (Chua \& Chang, 2016; Mascheroni et al., 2015; Tiidenberg \& Cruz, 2015). Therefore, research suggests that selfies are posted by young people to fulfil psychosocial needs in terms of identity play, affirmation and attractiveness.

Despite the growing body of research on the impact of social media per se on a number of aspects of psychological wellbeing (e.g., Holland \& Tiggemann, 2016; Richards et al., 2015) most of this research has been correlational. Furthermore, there remains little experimental research on the impact of selfie-posting and what research there is focuses mostly on self-esteem. Several theories, however, highlight the potential impact of both selfies and feedback in the form of 'likes', although studies have produced mixed results. For example, one view is that selfieposting may reduce self-esteem. In line with this, the objective self-awareness perspective (Frederick, Forbes, Grigorian, \& Jarcho, 2007) argues that viewing the self, increases self-surveillance and self awareness, highlighting personal flaws and damaging self-esteem. Increasing self-awareness is often achieved in research using mirrors (Fejfar \& Hoyle, 2000), although early research used images of the participant or exposure to a camera (Duval, Duval, \& Mulilis, 1992; Storms, 1973). As selfies include information that is similar to this stimuli, it is theorised that they too heighten self-awareness and decrease self-esteem.

In contrast, however, while increased self-surveillance may decrease self-esteem, research has found that viewing self-relevant information on social media actually improves self-esteem (Gonzales \& Hancock, 2011). This finds reflection in hyper personal theory (Walther, 1996) which argues that social media is perfect for optimal selfpresentation as it allows for refinement of self-image (Mehdizadeh, 2010). In line with this perspective, repeated exposure of a person to their 'better' self in a selfie, is proposed to promote an identity shift in which the optimised self is integrated into the self-concept thus increasing self-esteem (Gonzales \& Hancock, 2011). Some research supports this hyper personal perspective. For example, both qualitative and experimental studies show that individuals 'put their best selves forward' in selfies (Katz \& Crocker, 2015; Qui, Lin, Leung \& Tov, 2012) and that this optimal self-presentation can result in improved self-esteem (Gonzales \& Hancock, 2011; Tiidenberg \& Cruz, 2015). Therefore, whilst objective self awareness suggests that selfies may cause a deterioration in self-esteem, hyper personal theory suggests possible improvement.

Selfies, however, are not posted in isolation but often followed by feedback in the form of 'likes'. Sociometer theory (Leary \& Downs, 1995; Leary \& Baumeister, 2000) argues that cues of inclusion and rejection calibrate self-esteem. The reception of 'likes' may be regarded as a cue of inclusion, improving self-esteem, while the absence of likes may be regarded a cue of rejection, negating self-esteem. In support of this hypothesis, much research suggests that self-esteem is altered by online and offline approval. For example, self-esteem is raised when an individual is included and popular (or at least imagined to be), (de Bruyn \& van den Boom, 2005; Dennisen, Penke, Schmitt \& Aken, 2008). Moreover, on social media, the reception of positive feedback predicts higher self-esteem, while negative feedback predicts lower self-esteem (Forest \& Wood, 2012; Valkenburg et al., 2006). As social media 'likes' represent approval and inclusion, it seems plausible that selfie 'likes' predict self-esteem. Certainly, people of high self-esteem report receiving more selfie 'likes' than do those of low self-esteem (Alblooshi, 2015), although these findings are correlational. Recent experimental research however, identifies a similar relationship with Burrow and Rainone (2016) reporting raised self-esteem after participants had been told that their selfie had received 'high likes' and reduced self-esteem following 'low likes'.

In summary, current research indicates that an increasing number of young people are posting selfies and that their motives relate to playing with their identity and gaining peer affirmation. Research has also explored the impact of posting selfies specifically on self-esteem although this research is often contradictory. For example, whilst self-surveillance may reduce self-esteem via objective self-awareness (Frederick et al., 2007), the repeated exposure to an optimal self-image in the selfie as suggested by hyper personal theory may be beneficial (Gonzales 
\& Hancock, 2011). Some studies have also drawn upon sociometer theory (Leary \& Baumeister, 2000) and addressed the impact of gaining feedback ('likes') on selfies and it has been suggested that this process may boost self-esteem if 'likes' are considered high (Burrow \& Rainone, 2016), or high in comparison to others (Mascheroni et al., 2015) or reduce self-esteem if 'likes' are absent.

There are, however, several problems with this research to date. First, many studies have used either qualitative methods or correlational designs which limit conclusions about causality. Second, when experimental designs have been used to enable causal conclusions, these studies have taken place in a laboratory setting which limits ecological validity as they do not reflect the 'real world' of a social media platform. Third, studies have not included a 'no-selfie posting' control group which limits conclusions about the impact of posting selfies per se. Further, most studies have focused on self-esteem as their outcome variable rather than the broader aspects of psychological wellbeing highlighted in the wider research on social media (e.g., Holland \& Tiggemann, 2016; Richards et al., 2015). In particular, in line with this broader research it is likely that outcomes such as body image and mood may be influenced by selfie posting. In addition, to date, no research has explored the independent and combined impact of both 'selfies' and 'likes' and finally, whilst some research has addressed the immediate impact of selfies and / or feedback, studies have not addressed changes in the longer term.

The present study therefore aimed to address these gaps in the existing literature. In particular, it used an experimental design to enable conclusions about causality. It was also based in a real-world social media platform (Instagram) to increase ecological validity and explored the impact of both selfie-posting and feedback. Furthermore, it included broader measures of psychological wellbeing focusing on self-esteem together with measures of face and appearance satisfaction and perceived attractiveness in line with research illustrating the impact of social media on body image (Holland \& Tiggemann, 2016) and mood (Fardouly, Diedrichs, Vartanian, \& Halliwell, 2015). In addition, the study also included 'no-selfie' controls, and participants were followed up one week after a 7 day intervention to explore changes in the longer term. The present study therefore aimed to complement existing research by evaluating the impact of both posting selfies and receiving selfie-feedback ('likes') upon a broader range of aspects of psychological wellbeing (self-esteem, attractiveness (face and appearance satisfaction, perceived attractiveness) and mood) after a one week period of posting selfies and following an additional week post intervention. Given the limitations of previous research only tentative predictions were made as follows: posting selfies with feedback would have a positive impact on outcomes (improved self esteem, attractiveness, mood); posting selfies with no feedback would have a negative impact on outcomes (reduced self esteem, attractiveness, mood); any improvements in outcomes would deteriorate as soon as the intervention stopped. No specific predictions about the impact of posting selfies per se were made due to the contradictory nature of existing research.

\section{Methods}

\section{Participants}

Participants were recruited via opportunity sampling, and online registration, and were eligible for course tokens for their participation if they were students. All participants were also entered for a prize draw. Participants were required to have a functioning smart phone with a camera, as well as the social media application 'Instagram'. Uptake for the study was slow and participants who declined to take part described fears of feeling exposed and the intensity of the study. Seventy eight participants (21 Male; 57 Female) were initially recruited for the study of which 30 were from a $6^{\text {th }}$ form College, and 30 from a University in the South East of England. A further 18 were graduates living in the North East of England. Of these, 19 participants were excluded due to attrition after time 1, or failure to post at least four selfies. The final sample therefore consisted of 59 young people (Male $=14 ; 23.7 \%$; Female $=45 ; 76.5 \%)$, with a mean age of $20.37(S D=2.66$; range 16-25), of whom $41(69.5 \%)$ were in full time education and 18 were graduates (30.5\%). In terms of ethnicity, 53 participants were White (89.8\%), 0 were Black $(0 \%), 5$ were Asian (8.5\%), and 1 identified with another ethnic group (1.7\%). The students were studying psychology ( $n=31 ; 55.9 \%)$, health psychology $(n=7 ; 11.9 \%)$ or nutrition ( $n=2 ; 3.4 \%)$. Outside of the study, participants reported posting a mean of 1.66 selfies per week $(S D=2.71$; range $0-20)$. 


\section{Design}

The study used a between and within-subjects experimental design. The between-subjects variable was condition (not posting selfies vs posting selfies and not receiving feedback vs posting selfies and receiving feedback), and the within-subjects variable was time (baseline (T1), end of the one week intervention (T2), one week after the intervention (T3)). Outcome variables were self-esteem; attractiveness (face satisfaction, appearance satisfaction, perceived attractiveness); mood (positive mood, negative mood).

\section{Procedure}

Pilot studies. Pilot work was undertaken to identify the rates of selfie posting and to check the feasibility of the study design. In the first pilot study, seven age-matched participants were followed on Instagram to record their selfie-posting tendencies and 'likes'. Results showed that participants posted an average of 1.3 selfies per week but had previously posted up to four in a week. Each selfie received an average of 24 'likes'. Consequently, it was decided that participants would be asked to post seven selfies on Instagram in total over one week, and any who posted over four would be retained for data analysis. This was considered to be a reasonable and realistic amount, but sufficiently larger than an average amount to create an impact. The second pilot investigated whether participants would be willing to post one selfie per day for one week on their Instagram feed. Five participants were approached, of which four refused, fearing looking 'vain' to Instagram followers. As a result, it was decided that participants would post selfies on an Instagram account created for them by the researcher. In the third pilot study, seven age-matched participants were randomly allocated to a non-selfie posting condition ( $n=4$, no selfies for one week) or selfie-posting condition ( $n=3$, one selfie per day for one week on an experimental account). All seven participants successfully complied. Although hashtags made selfies public, selfies received zero 'likes', presumably due to lack of followers on the new accounts. This lead to the final pilot to trial alternative methods of gaining 'likes'. In the final pilot study, the application 'Likes for Instagram' was trialled. The researcher posted images on an Instagram account for seven days, and the application was used to provide the appearance of 'likes' for each image posted. The app was found to produce above 50 likes per photo. As a result of these pilot studies one selfie per day for 7 days (and at least 4), on a researcher generated Instagram account using app generated 'likes' was used as the intervention.

These pilot studies illustrated two tensions for the researchers. First, the aim was to reflect the natural behaviour of selfie posting by asking participants to post a 'natural' number of selfies. However, given that participants were already posting selfies a purely 'natural' number of selfies would have had no impact. Therefore, a number of selfies was chosen which was 'natural' and reasonable but more than usual to have an impact. This reduced the ecological validity of the study but increased the likelihood of finding an effect in a sample for whom the intervention was not entirely novel. Second, the aim was to reflect the natural platform provided by a social media cite with the option for receiving 'likes'. However, given participants reluctance to post on their usual site and the absence of 'likes' on a new site, 'likes' were artificially generated through the app. This raises questions about how the participants made sense of these more artificial 'likes' and whether they were considered to be as affirming as more naturally occurring 'likes' from their own followers. This again reduces the ecological validity of the feedback intervention but was necessary in order to simulate the impact of receiving likes for the purpose of the study. Accordingly, these tensions reflect the problems with carrying out experimental research in a more naturalistic setting. As a result, ecological validity was compromised but conclusions about causality could still be drawn.

Main study. The study gained favourable ethical approval from the University Ethics Committee and took place on the same days (Mon-Sun) over two consecutive weeks (time 1 (baseline), time 2 (end of intervention) and time 3 (one week later)). Written informed consent was obtained from all participants prior to the study. Data was collected in 2017.

\section{Materials}

The study used the application 'Likes for Instagram' which is available to download on most smartphones. Once Instagram account details have been entered into the software, it provides the most recent Instagram post with high 'likes' (50-100) that are traceable to real accounts. 


\section{Measures}

Participants completed paper or online questionnaires at three time points: T1 (baseline questionnaire); T2 (after 1 week intervention); T3 (one week after the end of intervention). Reliability was assessed where appropriate using Cronbach's alphas at baseline and follow up.

Demographics (baseline only). Participants provided their age, sex, ethnicity, education, and if applicable, subject they studied at university (A-Level students were recorded as 'Psychology'). Participants also reported their selfie posting tendencies (average number of selfies they posted on social media per week, assessed on a scale of 0 to $8+)$.

Outcome variables (all 3 time points). Participants recorded how they had felt 'over the past week'.

Self-esteem. Self-esteem was measured using Rosenberg's (1979) 10 item questionnaire ranging from 'Strongly Agree' (1) to 'Strongly Disagree' (4) (Time $1 \mathrm{a}=.89$, Time $2 \mathrm{a}=.89$, Time $3 \mathrm{a}=.88$ ).

Attractiveness. This was assessed in terms of the following: Face satisfaction was measured using face items from the body cathexis scale (Furnham \& Greaves, 1994; 9 items: eyes, teeth, cheek bones, eyes, nose, smile, complexion, skin, hair) using a 5-point Likert scale ranging from 'Very Disappointed' (1) to 'Very Satisfied' (5) (Time $1 a=.63$, Time $2 a=.72$, Time $3 a=.79$ ); Appearance satisfaction was assessed using the 'overall appearance' item (Furnham \& Greaves, 1994) from the Body Cathexis Scale rated on a 5-point Likert scale ranging from 'Very Disappointed' (1) to 'Very Satisfied' (5); Perceived attractiveness was assessed using 3 items 'Pretty', 'Good looking', and 'Attractive' which were rated on a 5 point Likert scale ranging from 'Very slightly or not at all' (1) to 'Extremely' (5) (Time $1 a=.89$, Time $2 a=.92$, Time $3 a=.71$ ). This measure has been used in previous research, although the item 'sexy' was removed for this population (Ogden, Smith, Nolan, Moroney, \& Lynch., 2011).

Mood. Mood was assessed in terms of positive and negative mood using the PANAS_(Watson, Clark \& Tellegan, 1988) which consists of 20 items describing positive and negative mood states (e.g. Nervous, Active, Excited) which are rated a 5-point Likert scale ranging from 'Very slightly or not at all' (1) to 'Extremely' (5). This was used to create two outcome variables: Positive Mood (Time $1 a=.84$, Time $2 a=.86$, Time $3 a=.90$ ), and Negative Mood (Time 1 $a=.83$, Time $2 a=.86$, Time $3 a=.76$ ).

\section{The Interventions}

On recruitment participants were randomly allocated to one of three conditions as follows:

No selfie control. Participants just completed measures at three time points.

Selfie no feedback. Participants posted one selfie per day for Mon-Sun across one week. Any 'likes' obtained were achieved without the application.

Selfie with feedback. Participants posted one selfie per day for Mon-Sun across one week and received a high level of likes from the app Likes for Instagram.

The results showed that participants adhered to the intervention. The results showed an overall impact of condition on the number of selfies posted $(F[2,56]=284.00 ; p=.001)$ but whereas those in the selfie no feedback condition posted a similar level of selfies $(M=6.52 ; S D=1.17)$ compared to those in the selfie feedback condition $(M=6.31 ; S D=1.06$ ), both conditions involving selfies (with or without feedback) posted significantly more selfies than those in the no selfie control condition $(M=0.3 ; S D=0.48)$. Further, those in the selfie feedback condition received significantly more 'likes' $(M=58.54 ; S D=10.98)$ than those in the selfie no feedback condition $(M=1.56$; $S D=3.67 ; t=21.45 ; p=0.0001$ ). The results indicated no differences in demographics between the conditions suggesting that random allocation was successful (see Table 1). 


\begin{tabular}{|c|c|c|c|c|c|c|c|c|c|c|}
\hline & \multicolumn{3}{|c|}{$\begin{array}{l}\text { No selfies } \\
(n=21)\end{array}$} & \multicolumn{3}{|c|}{$\begin{array}{l}\text { Selfie No Feedback } \\
\qquad(n=19)\end{array}$} & \multicolumn{3}{|c|}{$\begin{array}{l}\text { Selfie Feedback } \\
\qquad(n=19)\end{array}$} & \multirow[t]{2}{*}{ Difference tests } \\
\hline & $N$ & $\%$ & $M(S D)$ & $N$ & $\%$ & $M(S D)$ & $N$ & $\%$ & $M(S D)$ & \\
\hline Sex & & & & & & & & & & $\chi^{2}[2]=1.31, p=0.52$ \\
\hline Male & 5 & 24 & & 3 & 16 & & 6 & 32 & & \\
\hline Female & 16 & 76 & & 16 & 84 & & 13 & 69 & & \\
\hline Age & & & $\begin{array}{l}20.33 \\
(3.01)\end{array}$ & & & $\begin{array}{l}20.32 \\
(2.14)\end{array}$ & & & $\begin{array}{l}20.47 \\
(2.87)\end{array}$ & $F[2,56]=0.02, p=0.98$ \\
\hline Education & & & & & & & & & & $\chi^{2}[2]=3.09, p=0.54$ \\
\hline Full-Time Education & 15 & 71 & & 14 & 74 & & 12 & 63 & & \\
\hline Employed Graduates & 6 & 29 & & 5 & 26 & & 7 & 37 & & \\
\hline Subject & & & & & & & & & & $X^{2}[3]=13.6, p=0.32$ \\
\hline Psychology & 12 & 57 & & 9 & 47 & & 12 & 63 & & \\
\hline Health Psychology & 4 & 19 & & 3 & 16 & & 0 & 0 & & \\
\hline Nutrition & 1 & 5 & & 0 & 0 & & 1 & 5 & & \\
\hline N/A & 4 & 19 & & 7 & 37 & & 6 & 32 & & \\
\hline Ethnicity & & & & & & & & & & $\chi^{2}[3]=5.06, p=0.28$ \\
\hline White & 19 & 91 & & 16 & 84 & & 18 & 95 & & \\
\hline Black & 0 & 0 & & 0 & 0 & & 0 & 0 & & \\
\hline Asian & 2 & 10 & & 3 & 16 & & 0 & 0 & & \\
\hline Others & 0 & 0 & & 0 & 0 & & 1 & 6 & & \\
\hline Average Selfies per week & & & $\begin{array}{l}1.82 \\
(4.28)\end{array}$ & & & $\begin{array}{c}1.43 \\
(1.25)\end{array}$ & & & $\begin{array}{l}1.71 \\
(1.34)\end{array}$ & $F[2,56]=0.10, p=0.90$ \\
\hline
\end{tabular}

\section{Results}

\section{Data Analysis}

Data was screened for normality and mean scores were computed for all outcomes. Face satisfaction was kurtotic at time 1 and time 3 so change scores were calculated between all three time points and Kruskal-Wallis was used to compare change scores by condition. The remaining data were analysed using Repeated Measures ANOVA to assess the impact of condition (no selfie vs selfie no feedback vs selfie with feedback) and time (T1 vs T2 vs T3) on outcome variables (self-esteem, attractiveness, mood). Significant effects were further explored with post hoc tests.

\section{Impact of Condition and Time on Outcome Variables}

The results showing the impact of condition and time on the outcome variables are shown in Table 2 .

Self esteem. The results showed a significant effect of time on self esteem but no main effect of condition or condition by time interaction. Overall all participants, regardless of condition, showed a deterioration in the self esteem throughout the study.

Attractiveness. The results showed a main effect of time on appearance satisfaction but not for perceived attractiveness. No main effects of condition were found for either of these variables. The results also showed a significant condition by time interaction for appearance satisfaction. Post-hoc tests within each condition indicate that participants in the no selfie condition showed a steady increase in their appearance satisfaction between $\mathrm{T} 2$ and T3 $(p=.003)$ and between T1 and T3 $(p=.004)$ whereas those in the selfie feedback and selfie no feedback conditions reported no change in appearance satisfaction between any of the three time points (all $p>.05$ ). When exploring differences in change across the conditions the results showed that the improvement in appearance satisfaction between T1-T2 was greater in the no selfie condition compared to the change for those in either the selfie no feedback condition ( $p=.04)$ and the selfie feedback conditions $(p=.01)$ with both these groups showing no change in appearance satisfaction at this stage of the study. Similarly, the improvement in appearance 
satisfaction between T1-T3 was also greater for those in the no selfie condition compared to those in the selfie no feedback condition $(p=.005)$ and the self feedback condition $(p=.04)$. Accordingly, whilst those in the no selfie condition showed an improvement in appearance satisfaction throughout the three time points of the study those taking selfies (regardless of feedback) showed no change.

Table 2. Impact of Condition and Time on Outcome Variables (KW or Repeated Measures ANOVA (M/SD/ F, p, $\left.\eta^{2} p\right)$.

\begin{tabular}{|c|c|c|c|c|c|c|c|c|c|c|c|c|}
\hline & \multicolumn{3}{|c|}{$\begin{array}{c}\text { No selfie } \\
(n=20)\end{array}$} & \multicolumn{3}{|c|}{$\begin{array}{l}\text { Selfie no feedback } \\
\qquad(n=19)\end{array}$} & \multicolumn{3}{|c|}{$\begin{array}{l}\text { Selfie and feedback } \\
\qquad(n=19)\end{array}$} & \multirow[t]{2}{*}{$\begin{array}{l}\text { ME } \\
\text { Cond }\end{array}$} & \multirow[t]{2}{*}{$\begin{array}{c}\text { ME } \\
\text { Time }\end{array}$} & \multirow[t]{2}{*}{$\begin{array}{l}\text { Cond } x \\
\text { Time }\end{array}$} \\
\hline & Time 1 & Time 2 & Time 3 & Time 1 & Time 2 & Time 3 & Time 1 & Time 2 & Time 3 & & & \\
\hline & $M(S D)$ & $M(S D)$ & $M(S D)$ & $M(S D)$ & $M(S D)$ & $M(S D)$ & $M(S D)$ & $M(S D)$ & $M(S D)$ & $F ; p ; \eta^{2}{ }_{p}$ & $F ; p ; \eta_{p}^{2}$ & $F ; p ; \eta^{2} p$ \\
\hline \multirow[t]{3}{*}{ Self-Esteem } & 2.12 & 2.08 & 1.98 & 2.24 & 2.20 & 2.10 & 2.26 & 2.04 & 2.02 & 0.34 & 4.20 & 0.39 \\
\hline & $(0.57)$ & $(0.48)$ & $(0.45)$ & $(0.44)$ & $(0.41)$ & $(0.48)$ & $(0.67)$ & $(2.10)$ & $(0.58)$ & 0.72 & 0.02 & 0.81 \\
\hline & & & & & & & & & & 0.01 & 0.07 & 0.01 \\
\hline Appearance & 2.52 & 2.76 & 3.14 & 2.84 & 2.89 & 2.84 & 2.68 & 2.95 & 2.78 & 0.08 & 4.06 & 2.97 \\
\hline \multirow[t]{2}{*}{ Satisfaction } & $(0.68)$ & $(0.63)$ & $(0.58)$ & $(0.50)$ & $(0.56)$ & $(0.50)$ & $(0.75)$ & $(0.52)$ & $(0.63)$ & 0.92 & 0.02 & 0.02 \\
\hline & & & & & & & & & & 0.01 & 0.07 & 0.96 \\
\hline Perceived & 2.73 & 2.82 & 3.04 & 2.41 & 2.54 & 2.31 & 2.92 & 3.24 & 2.85 & 3.07 & 1.28 & 1.37 \\
\hline \multirow[t]{2}{*}{ Attractiveness } & $(0.83)$ & $(0.94)$ & $(0.79)$ & $(0.85)$ & $(0.77)$ & $(0.71)$ & $(1.02)$ & (1.05) & $(0.72)$ & 0.06 & 0.28 & 0.25 \\
\hline & & & & & & & & & & 0.11 & 0.03 & 0.05 \\
\hline Face & 2.69 & 2.74 & 2.93 & 2.68 & 2.64 & 2.75 & 2.71 & 2.82 & 2.71 & T1-T2 & $X^{2}=10.07(p=.007)$ & \\
\hline \multirow[t]{2}{*}{ satisfaction* } & 0.36 & 0.38 & 0.33 & 0.36 & 0.31 & 0.48 & 0.47 & 0.51 & 0.47 & T2-T3 & $X^{2}=6.22(p=.04)$ & \\
\hline & & & & & & & & & & T1-T3 & $\mathrm{X}^{2}=0.87(p=.65)$ & \\
\hline Positive & 3.27 & 3.09 & 3.27 & 3.09 & 2.78 & 3.04 & 3.18 & 3.21 & 3.22 & 1.29 & 2.04 & 0.64 \\
\hline \multirow[t]{2}{*}{ Mood } & $(0.59)$ & $(0.57)$ & $(0.54)$ & $(0.42)$ & $(0.62)$ & $(0.74)$ & $(0.82)$ & $(0.69)$ & $(0.84)$ & 0.28 & 0.14 & 0.63 \\
\hline & & & & & & & & & & 0.04 & 0.03 & 0.02 \\
\hline \multirow[t]{3}{*}{ Negative Mood } & 2.31 & 2.32 & 2.11 & 2.31 & 2.13 & 2.02 & 2.1 & 2.01 & 1.99 & .30 & 6.70 & 0.74 \\
\hline & $(0.78)$ & $(0.85)$ & $(0.49)$ & $(0.72)$ & $(0.77)$ & $(0.53)$ & $(0.58)$ & $(0.51)$ & $(0.60)$ & .745 & 0.01 & 0.56 \\
\hline & & & & & & & & & & 0.01 & 0.11 & 0.03 \\
\hline
\end{tabular}

Note: *Kruskal-Wallis was used to examine the differences in face satisfaction. Significant results are highlighted in bold.

For face satisfaction, analysis using Kruskal Wallis indicated significant differences by condition for changes between T1-T2 and T2-T3 but not between T1-T3. Post-hoc tests showed that those in the selfie feedback condition reported a greater increase in face satisfaction between T1-T2 compared to those in both the no selfie $(p=.02)$, and selfie no feedback conditions $(p=.0008)$. However, once the intervention was over those in the selfie feedback condition reported in decline in face satisfaction between T2-T3 which was a greater change than those in both the no selfie $(p=.02)$ and the selfie no feedback conditions $(p=.05)$ with both these latter conditions continuing to show some improvement after the intervention had ended.

Mood. The results showed a main effect of time for negative mood but not for positive mood and no main effect of condition for either variable. In addition, there were no condition by time interactions for either positive or negative mood. Overall, all participants, regardless of condition, showed a decrease in their negative mood throughout the study.

\section{Discussion}

Although 'selfies' have become an integral part of social media, there is only limited experimental research exploring their impact. The present study therefore aimed to explore the impact of posting selfies with and without feedback compared to posting no selfies on a number of aspects of psychological wellbeing using an experimental design with a further follow up after the intervention had ended. The results showed no impact of either posting selfies or receiving feedback on measures of self-esteem or positive or negative mood. These results conflict with much previous research which has indicated an association between selfie posting and reduced self-esteem (Burrow \& Rainone, 2016; Fejfar \& Hoyle, 2000) and mood (e.g. Fardouly et al., 2015; Richards et al., 2015). It also conflicts with research concluding that selfies might improve self esteem (Gonzales \& Hancock, 2011; Tiidenberg \& Cruz, 2015). Previous studies, however, were either qualitative and cross sectional in design or used a nonnaturalistic platform. Accordingly, the present study indicates that the predicted association between posting selfies and negative outcomes may not be as robust as predicted and may either be correlational or open to the impact of other confounding variables. 
The results from the present study did, however, show some impact of posting selfies and feedback on both appearance and face satisfaction. First, the results showed that those who posted no selfies showed a greater improvement in appearance satisfaction that those who posted selfies (regardless of feedback). This is in line with much research highlighting the detrimental impact of social media on body image (Holland \& Tiggemann, 2016) and suggests that specific concerns about appearance may be exacerbated through social media use. These findings also reflect the objective self awareness perspective (Frederick et al, 2007) and the notion that self surveillance through social media may be harmful. In contrast, the results, however, also showed some improvements in face satisfaction following the 7 day intervention involving both posting selfies on Instagram and receiving feedback in the form of 'likes' generated artificially through the app. This supports a hyper personal theory approach to social media (Gonzales \& Hancock, 2011) indicating that optimal self presentation may be advantageous. It also reflects the potential benefits of feedback and is in line with sociometer theory (Leary \& Baumeister, 2000) and both correlational and experimental research on the benefits of 'likes' (Alblooshi, 2015; Burrow \& Rainone, 2016). The results from the present study also showed, however, that these benefits were only short lived. In fact, as soon as the 7 day intervention was over, all improvement in face satisfaction was reversed with those in the selfie and feedback condition showing a deterioration in face satisfaction which was not only back their own baseline levels (pre intervention) but also greater and in the opposite direction to those in the other conditions. Accordingly, whilst posting selfies with feedback may result in a temporary improvement in face satisfaction this does not seem to persist. Further, it may be that the temporary improvement is itself damaging if it leads to a rebound effect afterwards.

Whilst being an experimental study there are some problems that need to be considered. First the sample was quite small which limits the generalisability of the findings and may have resulted in significant changes being missed. This was due to the intensity of the study design which led to drop outs throughout the study and the requirement that the study took place using a natural social media platform which resulted in lower uptake due to fears of feeling exposed. Accordingly, the benefits of an experimental design with a follow up and the use of a social media platform need to be balanced against a reduced sample size and the possibility that the study was under powered. Second, whilst improving ecological validity through the use of Instagram, this was compromised by the app to generate 'likes' and the requirement for participants to post more selfies than they usually would. This artificial method of generating 'likes' also raises questions about whether the 'likes' in the study had the same impact as those from real people who were known to the participant. Third, both men and women were included in the study but gender differences were not explored due to the limited sample size. The results, however, do illustrate the possibility of carrying experimental research in this field which enables some conclusions about causality to be drawn. Furthermore, the results highlight the need for longitudinal designs as any changes may vary over time.

\section{Conclusion}

To conclude, previous research suggests that social media may be detrimental for aspects of young people's psychological wellbeing. To date, however, research specifically on the impact of selfies is limited and most studies have used non-experimental designs. The results from this experimental study showed that whilst posting selfies with or without feedback had no impact on either self-esteem or mood, effects were found for outcomes more pertinent to the process of taking photos of the face with a detrimental effect on appearance satisfaction and a positive (albeit temporary) effect on face satisfaction when selfies were responded to with feedback in the form of 'likes'. Posting selfies may therefore result in a complex set of changes in how the individual feels about themselves which may be neutral, positive or negative depending upon what variable is measured and when.

\section{Acknowledgements}

The authors would like to thank the staff and students at Godalming College for their help with this study. 


\section{References}

Alblooshi, A. (2015). Self-esteem levels \& selfies: The relationship between self-esteem levels and the number of selfies people take and post, and the uses and gratifications of taking and posting selfies (Unpublished doctoral dissertation). Middle Tennessee State University, Murfreesboro, TN.

Arnett, J. J. (2000). Emerging adulthood: A theory of development from the late teens through the twenties. American Psychologist, 55, 469-480. http://dx.doi.org/10.1037/0003-066X.55.5.469

Bond, B. J. (2016). Following your "Friend": Social media and the strength of adolescents' Parasocial relationships with media personae. Cyberpsychology, Behavior, and Social Networking, 19, 656-660.

https://doi.org/10.1089/cyber.2016.0355

Burrow, A. L., \& Rainone, N. (2016). How many likes did I get? Purpose moderates links between positive social media feedback and self-esteem. Journal of Experimental Social Psychology, 69, 232-236.

https://doi.org/10.1016/j.jesp.2016.09.005

Chua, T. H. H., \& Chang, L. (2016). Follow me and like my beautiful selfies: Singapore teenage girls' engagement in self-presentation and peer comparison on social media. Computers in Human Behavior, 55, 190-197.

https://doi.org/10.1016/j.chb.2015.09.011

De Bruyn, E. H., \& van den Boom, D. C. (2005). Interpersonal behavior, peer popularity, and self-esteem in early adolescence. Social Development, 14, 555-573. https://doi.org/10.1111/j.1467-9507.2005.00317.x

Denissen, J. J. A., Penke, L., Schmitt, D. P., \& van Aken, M. A. G. (2008). Self-esteem reactions to social interactions: Evidence for sociometer mechanisms across days, people, and nations. Journal of Personality and Social Psychology, 95, 181-196. http://dx.doi.org/10.1037/0022-3514.95.1.181

Dhir, A., Pallesen, S., Torsheim, T., \& Andreassen, C. S. (2016). Do age and gender differences exist in selfierelated behaviours? Computers in Human Behavior, 63, 549-555. https://doi.org/10.1016/j.chb.2016.05.053

Duval, T. S., Duval, V. H., \& Mulilis, J.-P. (1992). Effects of self-focus, discrepancy between self and standard, and outcome expectancy favorability on the tendency to match self to standard or to withdraw. Journal of Personality and Social Psychology, 62, 340-348. http://dx.doi.org/10.1037/0022-3514.62.2.340

Fardouly, J., Diedrichs, P. C., Vartanian, L. R., \& Halliwell, E. (2015). Social comparisons on social media: The impact of Facebook on young women's body image concerns and mood. Body Image, 13, 38-45.

https://doi.org/10.1016/j.bodyim.2014.12.002

Fejfar, M. C., \& Hoyle, R. H. (2000). Effect of private self-awareness on negative affect and self-referent attribution: A quantitative review. Personality and Social Psychology Review, 4, 132-142.

https://doi.org/10.1207/S15327957PSPR0402_02

Forest, A. L., \& Wood, J. V. (2012) When social networking is not working: individuals with low self-esteem recognize but do not reap the benefits of self-disclosure on Facebook. Psychological Science, 23, 295-302. https://doi.org/10.1177/0956797611429709

Frederick, D. A., Forbes, G. B., Grigorian, K. E., \& Jarcho, J. M. (2007). The UCLA Body Project I: Gender and ethnic differences in self-objectification and body satisfaction among 2,206 undergraduates. Sex Roles, 57, 317-327.

https://doi.org/10.1007/s11199-007-9251-z

Furnham, A., \& Greaves, N. (1994). Gender and locus of control correlates of body image dissatisfaction. European Journal of Personality, 8, 183-200. https://doi.org/10.1002/per.2410080304 
Gonzales, A. L., \& Hancock, J. T. (2011). Mirror, mirror on my Facebook wall: Effects of exposure to Facebook on self-esteem. Cyberpsychology, Behavior, and Social Networking, 14, 79-83. https://doi.org/10.1089/cyber.2009.0411

Holland, G., \& Tiggemann, M. (2016). A systematic review of the impact of the use of social networking sites on body image and disordered eating outcomes. Body Image, 17, 100-110.

https://doi.org/10.1016/j.bodyim.2016.02.008

Katz, J. E., \& Crocker, E. T. (2015). Selfies and photo messaging as visual conversation: Reports from the United States, United Kingdom and China. International Journal of Communication, 9, 1861-1872. Retrieved from https://ijoc.org/index.php/ijoc/article/view/3180/1405

Leary, M. R., \& Baumeister, R. F. (2000). The nature and function of self-esteem: Sociometer theory. Advances in Experimental Social Psychology, 32, 1-62. https://doi.org/10.1016/S0065-2601(00)80003-9

Leary, M. R., Downs, D. L. (1995). Interpersonal Functions of the Self-Esteem Motive. In M. H. Kernis (Ed.), Efficacy, Agency, and Self-Esteem (pp. 123-144). Boston, MA: Springer.

Mascheroni, G., Vincent, J., \& Jimenez, E. (2015). "Girls are addicted to likes so they post semi-naked selfies": Peer mediation, normativity and the construction of identity online. Cyberpsychology: Journal of Psychosocial Research on Cyberspace, 9(1), article 5. http://dx.doi.org/10.5817/CP2015-1-5

Ogden, J., Smith, L., Nolan, H., Moroney, R., \& Lynch, H. (2011). The impact of an educational intervention to protect women against the influence of media images. Health Education, 111, 412-424.

https://doi.org/10.1108/09654281111161239

Qiu, L., Lin, H., Leung, A. K., \& Tov, W. (2012). Putting their best foot forward: Emotional disclosure on Facebook. Cyberpsychology, Behavior, and Social Networking, 15, 569-572. https://doi.org/10.1089/cyber.2012.0200

Richards, D., Caldwell, P. H., \& Go, H. (2015). Impact of social media on the health of children and young people. Journal of Paediatrics and Child Health, 51, 1152-1157. https://doi.org/10.1111/jpc.13023

Rosenberg, M. (1979). Conceiving the self. New York, NY: Basic Books.

Storms, M. D. (1973). Videotape and the attribution process: Reversing actors "and observers" points of view. Journal of Personality and Social Psychology, 27, 165-175. http://dx.doi.org/10.1037/h0034782

Tiidenberg, K., \& Gomez Cruz, E. (2015). Selfies, image and the re-making of the body. Body \& Society, 21(4), 77 102. https://doi.org/10.1177/1357034X15592465

Valkenburg, P. M., Peter, J., \& Schouten, A. P. (2006). Friend networking sites and their relationship to adolescents' well-being and social self-esteem. CyberPsychology \& Behavior, 9, 584-590.

https://doi.org/10.1089/cpb.2006.9.584

Walther, J. B. (1996). Computer-Mediated Communication: Impersonal, Interpersonal, and Hyperpersonal Interaction. Communication Research, 23(1), 3-43. https://doi.org/10.1177/009365096023001001

Watson, D., Clark, L. A., \& Tellegen, A. (1988). Development and validation of brief measures of positive and negative affect: The PANAS scales. Journal of Personality and Social Psychology, 54, 1063-1070.

https://doi.org/10.1037/0022-3514.54.6.1063

Weiser, E. B. (2015). \#Me: Narcissism and its facets as predictors of selfie-posting frequency. Personality and Individual Differences, 86, 477-481. https://doi.org/10.1016/j.paid.2015.07.007 


\title{
Correspondence to:
}

Jane Ogden (PhD)

Professor in Health Psychology

Department of Psychology (02AD27)

University of Surrey

Guildford

Surrey

GU2 7XH

United Kingdom

Email: J.Ogden(at)surrey.ac.uk

Editorial record: First submission received on January 17, 2018. Revisions received on August 22, 2018, and October 10, 2018. Accepted for publication on October 25, 2018.

The article is part of the Special Issue "Health and Technology" guest edited by Michal Molcho (NUI Galway), Christine Pellegrini (University of South Carolina), and Jana Holubcikova (PJ Safarik University). The manuscript was originally submitted to the journal's regular issue.

\begin{abstract}
About Authors
Naomi Coulthard is an alumnus of Psychology from the University of Surrey and an upcoming graduate of Clinical and Health Psychology (MSc) from the University of Manchester. A self-proclaimed 'people-watcher', Naomi is interested in the impact of social psychological processes upon young people's mental wellbeing. As a result of her recent work in an educational setting with teenagers, she intends to explore: (1) perceived stigma surrounding SEN and mental health, in educators and students, and (2) its impact on student wellbeing and academic attainment.

Jane Ogden is a Professor in Health Psychology at the University of Surrey, UK where she teaches psychology, nutrition, dieticians, vet and medical students to think psychologically about physical health. Her research areas focus in eating behaviour and weight management, communication and language and symptom perception. She has published over 190 research papers and 8 books.
\end{abstract}

